\title{
Secuenciamiento de las variantes del gen Kitlg a asociado a la pigmentación en el pez ornamental Platy (Xiphophorus maculatus, Günther, 1866)
}

\author{
Sequencing of the Kitlg a gene variants associated with pigmentation \\ in the ornamental Platyfish (Xiphophorus maculatus, Günther, 1866) \\ Recibido: mayo 12 de 2020 | Revisado: diciembre 12 de 2020 | Aceptado: enero 10 de 2021
}

Carlos ScotTo ${ }^{\mathrm{I}, 2}$

1 Laboratorio de Mejora Genética y Reproducción Animal de la Facultad de Ciencias Naturales y Matemática, Universidad Nacional Federico Villarreal.

2 Facultad de Ciencias de la Universidad Ricardo Palma. carlosscottoespinoza@ gmail.com
Resumen

La producción de peces ornamentales es una actividad importante dentro de la acuicultura peruana generando impactos socioeconómicos positivos en toda la cadena de valor. El pez ornamental Platy (Xiphophorus maculatus) es uno de los más coloridos peces ornamentales utilizados ampliamente como un sistema modelo animal para comprender la base genética del polimorfismo del patrón de color. La coloración en $X$. maculatus está relacionada con la síntesis de pigmentos de la melanina que afecta la coloración corporal. Se logró la amplificación e identificación molecular del polimorfismo genético de la secuencia del gen de la pigmentación Kitlg a (Kit Ligando a) en dos variedades del pez Platy (Tuxedo y Sunset Golden) que tuvieron 250 nucleótidos. Y cuyas secuencias se compararon con la secuencia del pez Cebra (Danio rerio) existente en el Genbank. Obteniéndose una secuencia de consenso de 176 nucleótidos siendo la relación de similitud más cercada entre las variedades del pez Platy que con respecto al $D$. rerio. Este primer reporte demuestra el potencial uso de la variabilidad en la secuencia del gen Kitlg a de X. maculatus y proporciona un enorme alcance en el campo de la acuicultura para mejorar la pigmentación del cuerpo de otros peces ornamentales de interés comercial.

Palabras clave: Kitlg, pigmentación, variabilidad genética, Xiphophorus maculatus

\begin{abstract}
The production of ornamental fish is an important activity within Peruvian aquaculture generating positive socioeconomic impacts throughout the value chain. The ornamental Platyfish (Xiphophorus maculatus) is one of the most colorful ornamental fish widely used as an animal model system to understand the genetic basis of color pattern polymorphism. The coloration in $X$. maculatus is related to the synthesis of melanin pigments that affects body coloration. The amplification and molecular identification of the genetic polymorphism of the Kitlg a pigmentation gene sequence (Kit Ligando a) was achieved in two varieties of Platy fish (Tuxedo and Sunset Golden) that had 250 nucleotides. And whose sequences were compared with the Zebrafish (Danio rerio) sequence existing in the Genbank. Obtaining a consensus sequence of 176 nucleotides, the relationship of similarity being closer between the varieties of the Platy fish than with respect to $D$. rerio. This first report demonstrates the potential use of variability in the Kitlg a gene sequence from $X$. maculatus and provides enormous scope in the aquaculture field to improve the body pigmentation of other ornamental fish of commercial interest.
\end{abstract}

Key words: Kitlg, pigmentation, genetic variability, Xiphophorus maculatus

(C) Los autores. Este artículo es publicado por la Revista Campus de la Facultad de Ingeniería y Arquitectura de la Universidad de San Martín de Porres. Este artículo se distribuye en los términos de la Licencia Creative Commons Atribución No-comercial - Compartir-Igual 4.0 Internacional (https://creativecommons.org/licenses/ CC-BY), que permite el uso no comercial, distribución y reproducción en cualquier medio siempre que la obra original sea debidamente citada. Para uso comercial contactar a: revistacampus@usmp.pe. 


\section{Introducción}

La identificación y caracterización genética de grupos de peces localmente adaptados y diferenciados es fundamental para preservar la variación genotípica en poblaciones naturales (Carvalho, 1993). Perú es considerado como uno de los 12 países megadiversos a nivel global, los que en conjunto alberga el $70 \%$ de la diversidad biológica del mundo. De las 117 zonas de vida reconocidas en el mundo, 84 se encuentran en el Perú con el primer lugar en diversidad de peces (Ley Peruana sobre la Conservación y Aprovechamiento Sostenible de la Diversidad Biológica, Ley No 26839).

La composición taxonómica de los peces continentales del Perú está conformada por 395 especies. De los cuales 393 son Characiformes o peces escamados (37\%), otras 393 especies son Siluriformes o bagres (37\%) y 83 especies son Gymnotiformes o peces eléctricos (8\%), los que en conjunto conforman el Super Orden Ostariophysi (82\%). Seguidamente, con una moderada riqueza se registran 91 especies de Perciformes (9\%) y 56 especies de Cyprinodontiformes (6\%). Finalmente, los órdenes: Clupeiformes (11 especies), Myliobatiformes (12 especies), Pleuronectiformes (seis especies), Beloniformes (cinco especies) y ocho órdenes más (12 especies en total) están también representados y conforman juntos un $4 \%$ de la ictiofauna continental peruana: En total, 1064 especies para el Perú (IIAP 2011; Ortega et al. 2012). Los peces ornamentales exóticos introducidos al Perú provienen, generalmente, de países africanos y asiáticos y corresponden a los órdenes Cypriniformes, Perciformes, Cyprinodontiformes y Characiformes y a las familias Cyprinidae, Osphronemidae, Cichlidae, Poecilidae y Characidae (Zafra et al. 2018).

La variación genética del grupo de peces neotropicales es extremadamente alta a nivel genético molecular (Farías et al., 2000). Existen diversos peces ornamentales que se encuentran distribuidos por todo el mundo, destacándose principalmente por su belleza y colorido los Sudamericanos, debido a la influencia de los factores medioambientales de este Continente comercial por presentar una mayor diversidad en intensidad en tonos $\mathrm{y}$ colores (Lessa, 1992).

Existe poco conocimiento sobre la estructura genética de estas poblaciones ícticas y de sus variedades de diversas familias de peces ornamentales cultivadas o capturadas en sus ambientes naturales. Muchas se encuentran en riesgo de desaparecer ya que están sometidas a una considerable presión, debido a la sobrepesca, sobrepoblación humana, contaminación de las fuentes de agua, deforestación de bosques y cambio climático. Por tal razón, estas especies deben ser consideradas para iniciar un programa de repoblación en donde hace muchos años era su hábitat natural (Kullander, 1998).

El pez ornamental Platy (Xiphophorus maculatus, Günther, 1866) se encuentra en América: desde México hasta el norte de Belice. Son peces muy populares en el mundo de la acuariofilia ya que no requieren cuidados especiales y tienen una capacidad excepcional de reproducirse. Los platys son peces ovovivíparos (los huevos permanecen en el interior de la hembra hasta su eclosión y, después, salen los alevines). Son muy fáciles de 
reproducir. Los machos persiguen a las hembras siempre con la intención de copular. La gestación tiene una duración aproximada de un mes. Esta parirá de 1 a 50 alevines que se valdrán por sí solos y que, desde el primer momento, irán en busca de alimento. A partir de los seis meses, los alevines ya serán sexualmente maduros (Moyle \& Cech, 2000).

La pigmentación y el patrón de color del cuerpo y las aletas cumplen múltiples funciones en los peces, incluido el camullaje, la comunicación, la elección de pareja o el reconocimiento de especies. La pigmentación de los peces es muy polimórfica y, a menudo, específica del sexo, especialmente durante la temporada de desove. Además, muchas especies de peces cambian su pigmentación durante su ciclo de vida. La coloración de los peces teleósteos se basa en seis tipos principales diferentes de células pigmentarias. A principios del siglo pasado, los poecílidos se hicieron populares entre los genetistas para estudiar la herencia de los patrones de color y también de los tumores derivados de las células pigmentarias (MacIntyre, 1961; Braasch \& Liedtke, 2011, Scotto, 2011).

Los peces ornamentales ganan un alto precio en el mercado debido a su cuerpo brillante y llamativa coloración. Esto se debe principalmente a la presencia de cromatóforos que se encuentran en la dermis, escamas, tegumento y ojos de pez. Hay dos tipos de cromatóforos a saber biocromos y esquemocromos. Los biocromos son verdaderos pigmentos, como los carotenoides (rojo, amarillo y naranja), pterinas (blanco, rojo, naranja y amarillo), purinas (blanco o plateado) y melaninas (rojos, amarillos, marrones y negros). Los cromatóforos que tienen el rojo y los carotenoides naranjas se denominan eritróforos, mientras que los carotenoides amarillos se denominan xantóforos. Los pigmentos de melanina se encuentran dentro de los cromatóforos llamados melanóforos. La melanina se obtiene por oxidación de aminoácidos como la tirosina y el triptófano. Un cuarto tipo de biocromo llamado pterinóforos, que tiene pterinas está involucrado en la coloración de los ojos y otros tejidos de los peces. Se han desarrollado varias especies de peces como sistemas modelo de primer nivel para la investigación de la expresión del color como es el caso del pez Platy (X. maculatus) (Goodwin, 1984; Abdul, 2020).

La coloración de fondo olivácea del pez Platy, Xiphophorus maculatus, se debe a la presencia de micromelanóforos intercalados entre pequeños xantóforos en la epidermis de las escamas y a la disposición de los micromelanóforos en patrón reticular en la dermis del flanco. Se han identificado dos loci autosómicos, St y $\mathrm{R}$, con dos alelos cada uno que controlan la presencia o ausencia de estas células pigmentarias. Los peces St_R_tienen la coloración de tipo salvaje. El genotipo St_rr, "pez gris", carece de xantóforos, pero el patrón de micromelanóforos es indistinguible del de los peces St. Los peces del genotipo ststR_ son amarillos por todas partes. Están prácticamente libres de micromelanóforos en las escamas y la dermis, pero el número de xantóforos se multiplica por muchas en las escamas. La dermis está poblada uniformemente por xantóforos. Por el contrario, los xantóforos están ausentes en estos dos tejidos en el pez St. Los peces recesivos dobles, stst rr, tienen un aspecto blanquecino, "fantasma” y carecen de micromelanóforos y de xantóforos en todo el tegumento. La existencia de varios linajes principales de células pigmentarias se puede discernir en 
X. maculatus y la acción de los loci St y $\mathrm{R}$ está restringida a solo una de estas líneas. El locus St de X. maculatus puede ser homólogo al locus $\mathrm{B}$ de Poecilia reticulata $\mathrm{y}$ el locus $\mathrm{R}$ de X. maculatus puede ser homólogo al locus $\mathrm{R}$ de $\mathrm{P}$. reticulata. No se ha identificado en $\mathrm{X}$. maculatus ningún gen homólogo al locus $\mathrm{G}$ de P. reticulata, que también afecta a los melanóforos y xantóforos (Kallman \& Brunetti, 1983; Basolo, 2006).

Un grupo de investigadores procedentes de varias universidades dirigidos por David Kingsley del Instituto Médico Howard Hughes publicó en la revista Cell, piezas de la maquinaria genética de la coloración en peces. Para el estudio utilizaron al pez Gasterosteus aculeatus, para comenzar a entender la base genética de los cambios de los diferentes patrones de pigmentación. Y encontraron que un gen llamado Kitlg que estaba asociado con la herencia de la pigmentación. Este gen permite la producción de una proteína que ayuda a mantener a los melanocitos. El Kitlg codifica receptores de factores de crecimiento epidermal que es necesario para la migración y sobrevivencia de los precursores de melanocitos. Sus mutaciones o variantes (alelos) pueden afectar la migración de los melanocitos alterando el patrón de coloración del animal. Así mismo, este gen en peces se presenta por duplicado a diferencia de los tetrápodos, lo cual puede hacer variar la expresión fenotípica del patrón cromático. Los peces espinosos han experimentado una de las radiaciones evolutivas más recientes y dramáticas en la tierra". Cuando la última era de la glaciación se terminó, los glaciares gigantes se derritieron y crearon miles de lagos y ríos en Norteamérica, Europa y Asia. Estas aguas fueron colonizadas por los antepasados marinos, que posteriormente se adaptaron a la vida en agua dulce. "Esto creó una multiplicidad de pequeños experimentos evolutivos, en los cuales estas poblaciones aisladas de peces se adaptaron a nuevas fuentes de alimento, depredadores, color del agua y temperatura del agua que encontraron en estos nuevos ambientes". Entre esas adaptaciones estaban las "nuevas coloraciones" que ayudaron a los peces a camuflarse, a distinguir especies y a atraer parejas en sus nuevos ambientes (Pielberg et al., 2002; Quigley \& Parichy, 2002; Hultman et al., 2007).

Existen casi una docena de genes que estarían contribuyendo al patrón cromático de los peces como son: SLC24A5, Mir, Tyrp1, Sox10, Mitf, Kitlg y Ednrb (Braasch, 2007). Hoy se sabe que algunas variantes del gen SLC24A5 está asociado con el color de ojos y cabello, y una variante del Kitlg está asociada con el color de cabello en humanos. Los estudios de la mutación en el pez Cebra variedad "Golden o Dorada" que aclaran el color normalmente oscuro del cuerpo del animal posee un 69\% de similaridad con el gen SLC24A5 de humano, lo cual demuestra su grado de conservación evolutiva de éste y otros genes asociados al color (Basolo, 2006; Miller et al., 2007: Izaguirre et al., 2006; Han et al., 2008).

Los patrones de pigmento de melanocitos en vertebrados se han estudiado durante mucho tiempo como un modelo para la formación de patrones y la morfogénesis. Los melanocitos surgen en la cresta neural e inmediatamente comienzan a migrar ventralmente a lo largo de distintas vías migratorias para establecer el patrón de pigmento embrionario. Los ratones con mutaciones nulas en el kit receptor de 
tirosina quinasa son letales en su versión homocigota dominante debido a la falla de la hematopoyesis. Sin embargo, los animales heterocigotos $\mathrm{u}$ homocigotos recesivos son viables, y muestran un fenotipo de color de pelaje blanco o falta de coloración o pigmentación (Sarvella $\&$ Russell, 1956). Existe un trabajo preliminar de amplificación del gen Kitlg por PCR en el pez Disco (Symphysodon aequifasciatus aequifasciatus) (Perciformes: Cichlidae) cuya banda aproximada fue de 1000 nucleótidos aproximadamente (Scotto et al., 2015).

El objetivo de la presente investigación fue la amplificación e identificación molecular del polimorfismo genético de la secuencia nucleotídica del gen Kitlg a (Kit Ligando a) en variedades del pez ornamental Platy (Xiphophorus maculatus, Günther, 1866) que está asociada al patrón de pigmentación de los peces ornamentales.

\section{Método}

\section{Extracción de ADN}

Dos variedades del pez ornamental dulceacuícola Platy (Xiphophorus maculatus) de la familia Poecilidae (Orden Cyprinodontiformes) fueron mantenidos en dos peceras con agua a una temperatura de $25^{\circ} \mathrm{C}, \mathrm{pH}: 7$ y una dureza de agua de $15^{\circ} \mathrm{dGH}$. Se sacrificó cada animal previo enfriamiento para producirle inconciencia. Se realizó la extracción de ADN de tejido muscular utilizando el Kit DNeasy Blood \& Tissue (Qiagen) con la ayuda de un escarpelo estéril (aproximadamente $100 \mathrm{mg}$ a $200 \mathrm{mg}$ ). El tejido muscular colectado fue colocado en un tubo Eppendorf de $1.5 \mathrm{ml}$ estéril para ser procesado con el kit de extracción de ADN. Se agregó 0,5 volúmenes de agua libre de nucleasas y se homogenizó. Se extrajo 50 ul del sobrenadante y se homogenizó. Se diluyó finalmente en 100ul de buffer de elución del Kit. Las muestras fueron corridas en un gel de agarosa al $1 \%$ para observar la calidad del ADN extraído y luego se cuantificó por espectrofotometría UV para obtener concentraciones de 90 a 170ng/ul. Cada muestra fue diluida a una concentración de $20 \mathrm{ng} / \mathrm{ul}$. Se sembró 3 ul de buffer de carga $3 \mathrm{X}$ más 6ul de ADN extraído en cada pocillo del gel de agarosa al $1 \%$.

\section{Amplificación por PCR}

Para la amplificación por PCR se trabajó con una concentración de 40ng/ul de cada muestra (volumen final de 10ul): 3ul de agua libre de nucleasas, 5 ul de Buffer Master Mix Rotor Gene Syber 2X, 0.5 ul de dNTPs (25nm), 0.5ul del primer Kitlg a Forward o Reverse (10 uM) y lul de muestra de ADN. Las condiciones de ciclaje para el PCR fueron las siguientes: Activación inicial de un ciclo por dos minutos a $95^{\circ} \mathrm{C}, 40$ ciclos de 20 segundos a $94^{\circ} \mathrm{C}$ para denaturación, 40 ciclos de 35 segundos a $59^{\circ} \mathrm{C}$ para alineamiento, un ciclo de 20 segundos a $72^{\circ} \mathrm{C}$ por 10 minutos, seguido por una extensión final de un ciclo a $4^{\circ} \mathrm{C}$. El producto amplificado fue analizado mediante una electroforesis en geles de agarosa al $1 \%$. Se sembró 3ul de buffer de carga 3X más 6ul de ADN extraído en cada pocillo del gel de agarosa. Se sembró 1.5 a 2 ul de amplificado en cada pocillo y corrió a $90 \mathrm{~V}$ por 50 minutos. Se utilizó un marcador de peso molecular de $1000 \mathrm{pb}$ comercial para identificar la banda amplificada de $250 \mathrm{pb}$. Para determinar la presencia del gen Kitlg se sintetizaron cebadores o primers específicos comerciales repor- 
tados por la literatura científica y cuyas secuencias fueron: Kitlga-F: 3'-CACAGTTGCTGCCTATTCCA-5' y Kitlga-R: 5'- TGAATCCTCCAAACCAGGTC-3'. El amplificado de Kitlg a $(250 \mathrm{pb})$ purificados y fueron enviados a secuenciar a una casa comercial especializada en el extranjero.

\section{Análisis molecular de las secuencias del gen Kitlg a}

Con la información molecular se editó y alineó las secuencias con el programa Bioedit (Versión 7.0.4, 2005). Y se construyó el árbol filogenético con el programa MEGA X (Kumar et al., 2018). Se compararon las secuencias nucleotídicas del Kitlg a de 250 nucleótidos de las dos variedades del pez ornamental Platy (Xiphophorus maculatus) con la secuencia nucleotídica del gen Kitlg a del pez Cebra (D. rerio) publicado en el Genbank (No. de acceso AY929068.1).

\section{Resultados y Discusión}

Si bien se tiene el genoma completo secuenciado del pez Espada (Xiphophorus helleri) (Schartl et al., 2013; Genbank, 2020b) que es el mismo género que el pez Platy (Xiphophorus maculatus) no se tiene investigaciones que liguen la variabilidad de los genes relacionados a la pigmentación y/o coloración con la variabilidad fenotípica del cuerpo y/o aletas de las distintas variedades que posee este género (Xiphophorus Genetic Stock, 2020) (Figuras 1).

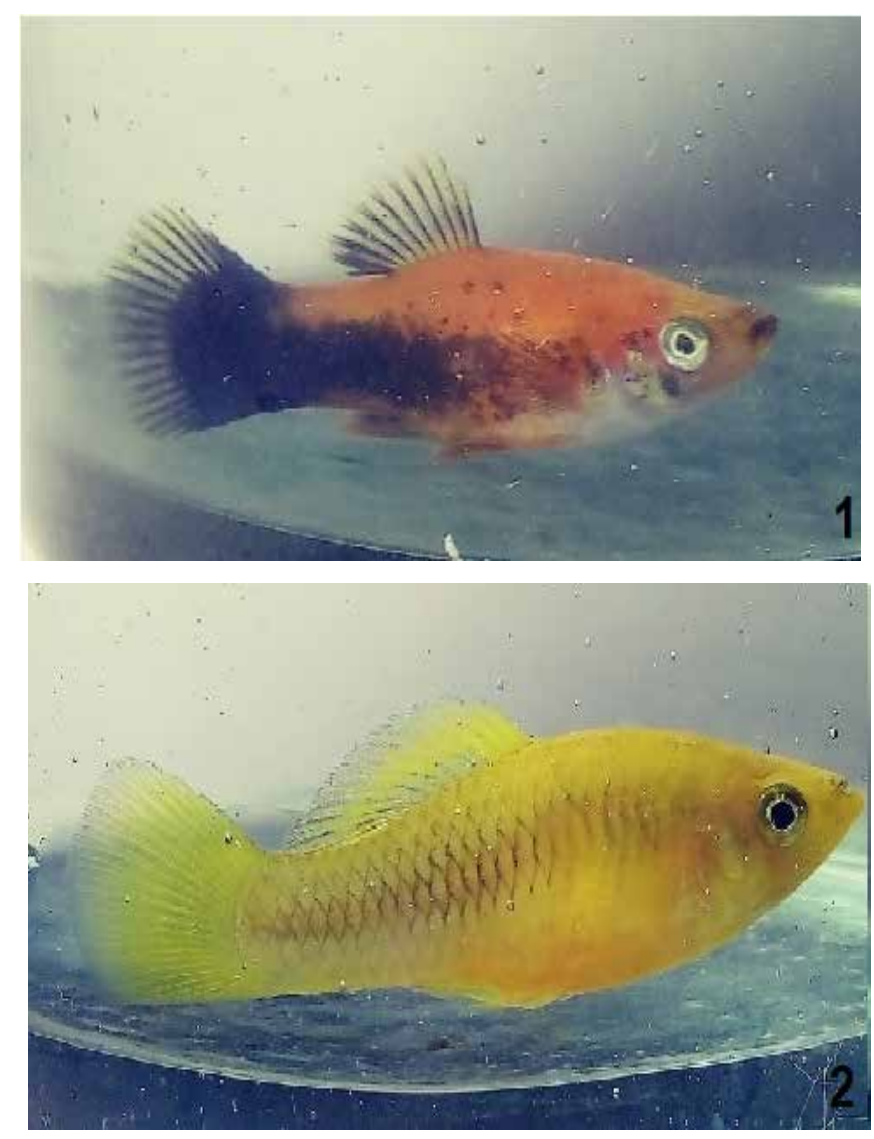

Figura 1. Variedades de peces Platys (Xiphophorus maculatus): 1 = Variedad "Tuxedo" y 2 = variedad "Sunset Golden". 
El proceso de extracción de $\mathrm{ADN}$ fue óptimo evidenciándose solo una banda muy detallada para el proceso de amplificación del gen Kitlg a por PCR.
La amplificación por PCR dio bandas de una longitud aproximada de $250 \mathrm{pb}$ para ambas variedades (Figura 2).

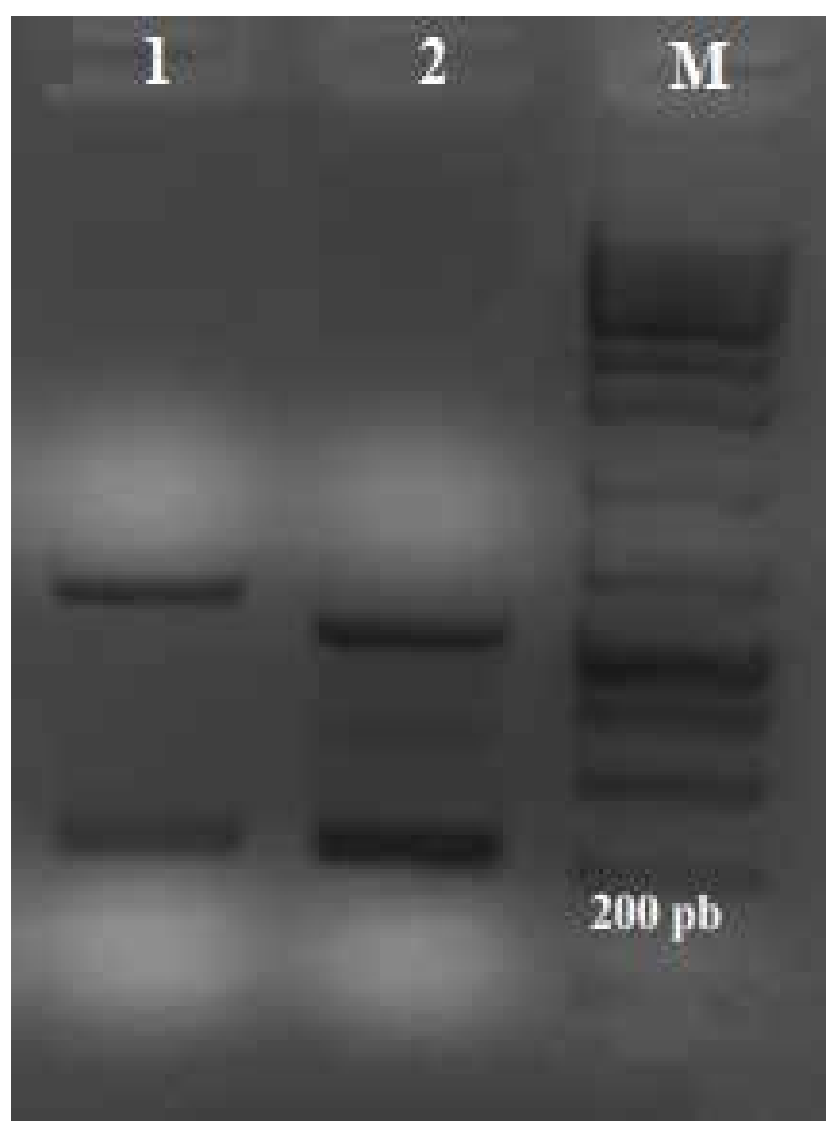

Figura 2. Gel de amplificado de las variedades de peces Platys (Xiphophorus maculatus): 1 = Variedad "Tuxedo"; 2 = Variedad "Sunset Golden". Marcador de peso molecular de $1000 \mathrm{pb}$.

El resultado del secuenciamiento logró identificar la secuencia nucleotídica del gen Kitlg a en las dos variedades del pez ornamental Platy no antes reportado. Se utilizó como referencia la secuencia reportada en el Genbank del gen de Kit Ligando del pez Cebra (Genbank, 2020a). Se comparó con las secuencias de las variedades "Tuxedo" y "Sunset Gold" de Platy en el programa Bioedit. Se alineó y eliminó los "Gaps" quedando una secuencia consenso de 178 nucleótidos. Con el programa MEGA se realizó el análisis filogenético. En la Figura 3, se observa el árbol filogenético obtenido de la comparación de las secuencias del gen de Kitlg a con las variedades "Tuxedo" y "Sunset Gold" de Platy. 


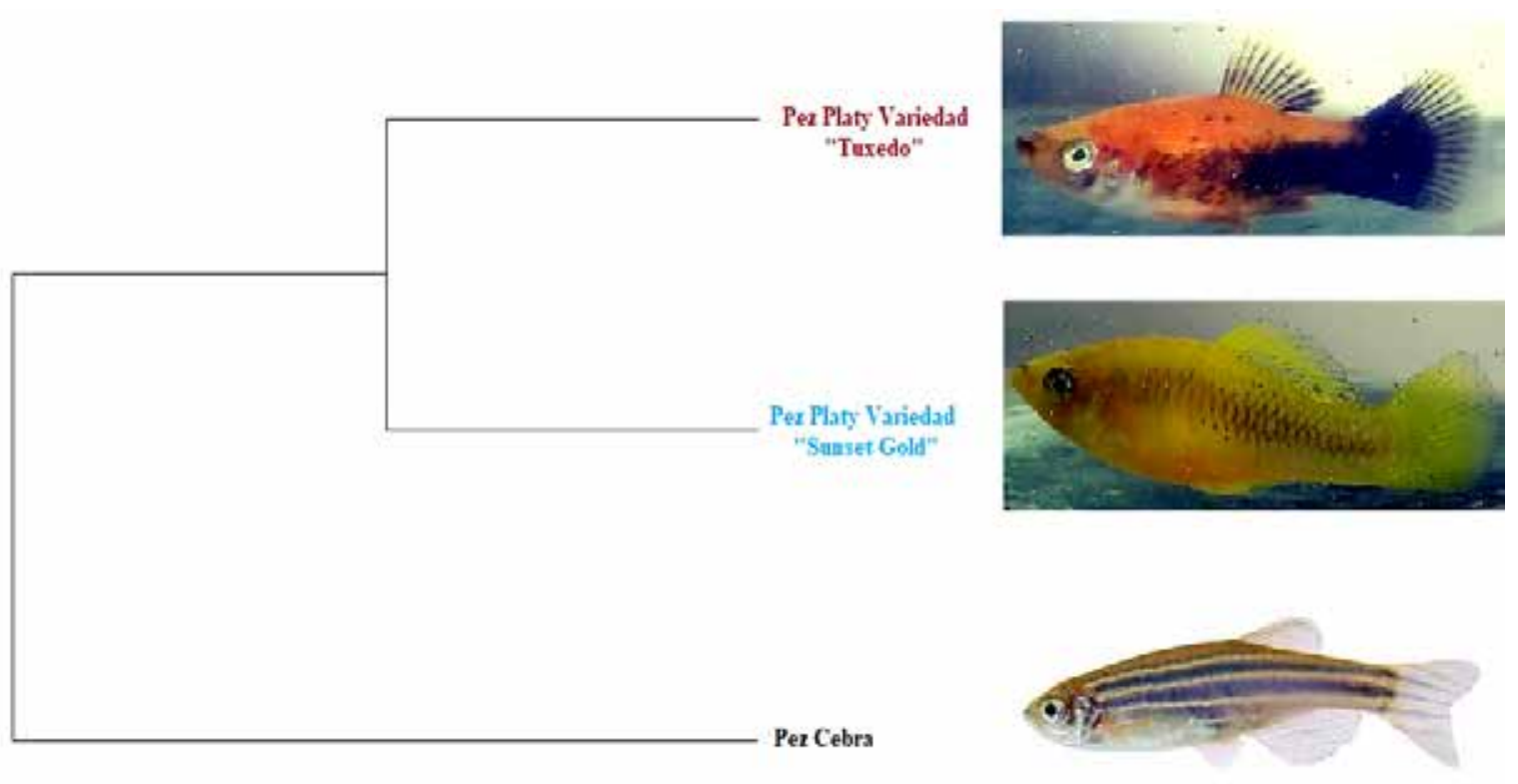

Figura 3. Árbol filogenético obtenido de las secuencias del gen Kitlg a de las variedades "Tuxedo" y "Sunset Gold” del pez Platy (Xiphophorus maculatus) y del pez Cebra (Danio rerio).

Es así, que se encontró más similitud entre la secuencia nucleotídica del gen Kitlg a de las dos variedades del pez Platy (Tuxedo y Sunset Golden) con cerca de $32.59 \%$. Quecon respecto a la secuencia del pez Cebra que fue de $17.67 \%$ de similitud (Figura 3). A nivel de la secuencia de aminoácidos se tiene la misma correlación pues existe mayor similitud entre las secuencias de aminoácidos de las dos variedades analizadas (cinco aminoácidos conservados) que con respecto a la secuencia de aminoácidos del pez Cebra (tres aminoácidos) (Figura 4). Aspecto que ya ha sido reportado por varios autores en las diversas variedades de pigmentación en otras especies (Rajaraman et al., 2000; Pielberg et al., 2002; Basolo, 2006; Izagirre et al., 2006; Sulem et al., 2007; Han et al., 2008; Weich et al., 2020).

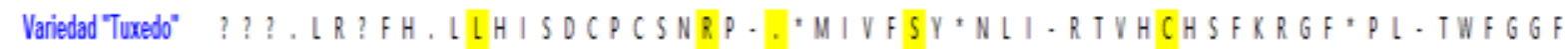

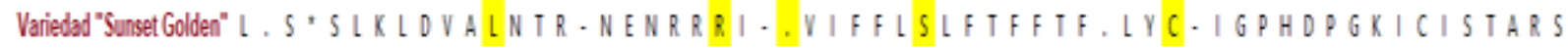

Figura 4: Comparación de la secuencia de aminoácidos del gen de Kitlg a entre las variedades Tuxedo y Sunset Golden del pez Platy. De color amarillo se representan los aminoácidos conservados con código de una sola letra.

\section{Conclusiones}

Todas las muestras de las dos variedades de colores del pez Platy (Xiphophorus maculatus) amplificaron en una banda para el gen de Kitlg a con una secuencia de una longitud de $250 \mathrm{pb}$ aproximadamente. Las secuencias fueron utilizadas para determinar su identidad molecular mediante el programa Bioedit.
Todas las secuencias se corresponderían con el gen de Kitlg a del pez Cebra asociado a la pigmentación corporal del Genbank (No. de Acceso AY929068.1). Del análisis filogenético, los resultados para el gen de la Kitlg a evidenciaron una similitud de la secuencia de nucleótidos de $32.59 \%$ entre las variedades Tuxedo y Sunset Golden del pez Platy. Y ambas una similitud de $17.67 \%$ con la secuencia 
del pez Cebra. A nivel de la secuencia de aminoácidos existe una mayor similitud entre las secuencias de aminoácidos de las dos variedades del pez Platy (cinco aminoácidos conservados) que con respecto a la secuencia de aminoácidos del pez Cebra (tres aminoácidos conservados).

\section{Referencias}

Abdul Khader Sultan Mohideen, Anbu Arun. (2020). Bioinformatics Analysis of the Melanocortin 1 Receptor Gene (MC1R) in the Southern Platyfish Xiphophorus maculatus (Günther, 1866), Int J Bioautomation, 24(3): 235-244, DOI: 10.7546/ ijba.2020.24.3.000609

Basolo, A. (2006). Genetic Linkage and Color Polymorphism in the Southern Platyfish (Xiphophorus maculatus): A Model System for Studies of Color Pattern Evolution. Zebrafish. Volume 3 (1): 65-83. DOI: 10.1089 / zeb.2006.3.65

BioEdit (2005). Versión 7.0.4. Copyright (C) 1997-2005, Tom Hall. En: http://www.mbio.ncsu.edu/ BioEdit/bioedit?.html.

Braasch, I.; Schartl, M. \& Volff, J. (2007). Evolution of pigment synthesis pathways by gene and genome duplication in fish. BMC Evolutionary Biology. 7(74):14-18. En: https://doi.org/10.1186/14712148-7-74

Braasch, Ingo \& Liedtke, Daniel. Genes del pigmento y genes del cáncer. En el libro: Enciclopedia de fisiología de los peces: del genoma al medio ambiente, volumen 3era. Edición. Editorial: Academic Press. Junio de 2011.
Carvalho, G. R. (1993). Evolutionary aspects of fish distribution: genetic variability and adaptation. Journal of Fish Biology. 43:53-73. En: https://doi. org/10.1111/j.1095-8649.1993. tb01179.x

Encyclo Fish. En: https://www.encyclofish.com/EN/freshwater/fishes/ xiphophorus-maculatus.php

Farías, I. P., G., Ortí \& A., Meyer. (2000). Total evidence: Molecules, morphology, and the phylogenetics of cichlid fishes. Journal of experimental zoology. 288:76-92. En: DOI: 10.1002 / (SICI) $1097-$ 010X (20000415) 288: $1<76$ :: AID-JEZ8> 3.0.CO; 2-P

Genbank. (2020a). Secuencia del Kit ligando a (Kitla) de pez Cebra (Danio rerio), No. de acceso: AY929068.1 En: https://www. ncbi.nlm.nih.gov/nuccore/ AY929068.1? report=fasta

Genbank (2020b). kit ligando a Xiphophorus hellerii (Cola de espada verde). No. de acceso: NC_045673.1. En: https:// w w w . n c bi . n l m . n i h.gov/ gene/116708098/

Genbank. (2020c). Xiphophorus hellerii cepa 12219 cromosoma 4, Xiphophorus_hellerii-4.1, 
secuencia del genoma completo. No. de acceso:NC_045675. Disponible en: https://www.ncbi.nlm.nih.gov/ nuccore/NC_045675.1

Han, J.; Kraft, P.; Nan, H.; Guo, H.; Chen, C.; Qureshi, A.; Hankinson, E.; Hu, F.; Duffy, D.; Zhao, Z.; Martin, N.; Montgomery, G.; Hayward, N. \& Hunter, A. (2008). Genome-Wide association study identifies novel alleles associated with hair color and skin pigmentation. Volume 4: 1-11. En: https://doi.org/10.1371/journal. pgen. 1000074

Hultman, K.; Bahary, N.; Zon, L \& Johnson, S. (2007). Gene duplication of the zebrafish kit ligand and partitioning of melanocyte development functions to kit ligand a. PLoS Genetics. Volume 3 (1): 89-102. En: https://doi.org/10.1371/journal. pgen.0030017

\section{INSTITUTO}

DE INVESTIGACIONES DE LA AMAZONÍA PERUANA (IIAP). (2011). Peces ornamentales amazónicos. Catálogo 2011. 72 pp. Instituto de Investigaciones de la Amazonía Peruana- IIAP. [acceso: 20/5/2019]. En: http://repositorio. iiap.org.pe/bitstream/IIAP/138/1/ sanchez_libros_2011.pdf

Izaguirre, N.; García, I.; Junquera, C.; De la Rua, C. \& Alonso, S. (2006). A scan for signatures of positive selection in candidate loci for skin pigmentation in humans. Mol. Biol. Evol. 23(9):1697-1706. DOI: $10.1093 / \mathrm{molbev} / \mathrm{msl} 030$
Kallman, Klaus \& Brunetti, Valerie (1983). Base genética de tres variedades de colores mutantes de Xiphophorus maculatus: el platy gris, dorado y fantasma. Copeia, Vol. 1983(1):170-181. DOI: $10.2307 / 1444711$

Kullander, S. O. (1998). A phylogeny and classification of the South American Cichlidae (Teleostei: Perciformes). p. 462. In: Malabarba, L. R., R. E., Reis, R. P., Vari, Z. M. S., Lucena \& C. A .S., Lucena (ed.), Phylogeny and Classification of Neotropical Fishes. EDIPUCRS. Porto Alegre, Brasil.

Kumar, S., Stecher, G., Li. M., Knyaz, C. \& Tamura, K. (2018). MEGA X: Molecular Evolutionary Genetics Analysis across computing platforms. Molecular Biology and Evolution, 35:1547-1549. DOI: 10.1093 / molbev / msy096

Lessa, E. P. (1992). Rapid surveying of DNA sequence variation in Natural populations. Molecular Biology and Evolution. 9(2):323-330. DOI: 10.1093 / oxfordjournals. molbev.a040723

Ley $\mathrm{N}^{\circ} 26839$. Ley sobre la conservación y aprovechamiento sostenible de la diversidad biológica. En: http://www.minam.gob.pe/wpcontent/uploads/2017/04/LeyN\%C2\%B0-26839.pdf

MacIntyre, Pamela. (1961). Crossing over within the macromelanophore gene in the Platyfish, Xiphophorus maculatus. The American Naturalist, Vol. XCV(884):323. https://doi.org/10.1086/282193 
Miller, C.; Beleza, S.; Pollen, A.; Schluter, D.; Kittles, A.; Shriver, M. \& Kingsley, D. (2007). cisregulatory changes in kit ligand expression and parallel evolution of pigmentation in sticklebacks and humans. Cell. 131 (6):1179-1189. DOI: $10.1016 /$ j.cell.2007.10.055

Moyle, P. \& J. Cech. Fishes: An Introduction to Ichthyology, $4^{\mathrm{a}}$ edición, Upper Saddle River, Nueva Jersey, Estados Unidos: PrenticeHall. 2000.

Ortega, H., Hidalgo, M., Trevejo, G., Correa, E., Cortijo, A., Meza, V. \& Espino, J. (2012). Lista anotada de los peces de aguas continentales del Perú: Estado actual del conocimiento, distribución, usos y aspectos de conservación. Ministerio del Ambiente, Dirección General de Diversidad Biológica Eds. Museo de Historia Natural de la UNMSM. 2da. ed. Lima, Perú.

Parichy, D. M., Rawls, J. F., Pratt, S. J., Whitfield, T. T. \& Johnson, S. L. (1999).Zebrafishsparsecorresponds to an orthologue of c-kit and is required for the morphogenesis of a subpopulation of melanocytes, but is not essential for hematopoiesis or primordial germ cell development. Development 12: 3425-3436. En: https://dev.biologists.org/ content/126/15/3425.long

Pielberg, G.; Olsson, C.; Syvanen, A. \& Andersson, L. (2002). Unexpectedly high allelic diversity at the kit locus causing dominant white color in the domestic pig. Genetics, 160: 305-311. En: https://www.ncbi.nlm.nih.gov/ pmc/articles/PMC1461930/

Quigley, I. \& Parichy, D. (2002). Pigment Pattern Formation in Zebrafish: A Model for Developmental Genetics and the Evolution of Form. Microscopy Research and Technique. 58:442-455.En:https:// doi.org/10.1002/jemt. 10162

Rajaraman, S.; Davis, W.; MahakaliZama, A.; Evans, H.; Russell, L \& Bedell, M. 2000. An allelic series of mutations in the kit ligand gene of mice. I. Identification of point mutations in seven ethylnitrosourea-induced kitlsteel alleles. Genetics 162: 331-340. En: https://www.genetics.org/ content/162/1/341

Sarvella, P. \& Russell, L. (1956) Steel, un nuevo gen dominante en el ratón doméstico. J Hered, 47: 123-128.

Schartl, M., Walter, R., Shen, Y. et al. (2013). El genoma del pez Platy, Xiphophorusmaculatus, proporciona información sobre la adaptación evolutiva y varios rasgos complejos. Nat Genet, 45:567-572. https:// doi.org/10.1038/ng.2604

Scotto, Carlos. (2011). Obtención de un patrón cromático digital para ser utilizado en la mejora genética por selección masal de la variedad Half Black Blue o Diamante del pez ornamental Guppy (Poecilia reticulata; Peters, 1859). Revista Scientia Agropecuaria. Vol. 2(01) 139 - 148. DOI: http://dx.doi.org/10.17268/sci. agropecu.2011.03.03 
Scotto, C., Angeles, B. \& Miglio, M. C. (2015). Amplificación e identificación molecular del polimorfismo genético de los genes de color Kitlg y Tyrp1b en los peces de la amazonía peruana Symphysodon aequifasciatus aequifasciatus y Festivus (Mesonauta festivus) (Perciformes: Cichlidae). Revista Cátedra Villarreal. Vol. 3 (1): 37-46. DOI: http://dx.doi. org/10.24039/cv20153143

Sulem, P.; Gudbjartsson, D.; Stacey, S.; Helgason, A.; Rafnar, T.; Magnusson, K.; Manolescu, A. \& Karason, A. (2007). Genetic determinants of hair, eye and skin pigmentation in Europeans. Nature Genetics. Vol. 39 (12): 1443-1452. DOI: $10.1038 /$ ng.2007.13
Weich, K., Affolter, V., York, D., Rebhun, R., Grahn, R., Kallenberg, A. \& a Bannasch, D. (2020). Pigment intensity in dogs is associated with a copy number variant upstream of Kitlg. Genes, Vol. 11(75):113. En: https://doi.org/10.3390/ genes 11010075

Xiphophorus Genetic Stock Center (XGSC). En: http://www. xiphophorus.txstate.edu/

Zafra, A., Díaz, M., Dávila, F., Vela, K. \& Colchado, J. (2018). Catálogo de peces ornamentales en Trujillo, La Libertad, Perú. Arnaldoa 25(2): 757-786. En: http://dx.doi. org/http://doi.org/10.22497/ arnaldoa.252.25221. 